\title{
An analytical study on behavioral-cerebral system activities and alexithymia among
} drug abused and none drug abused people

Jahanshah Mohammadzadeh ${ }^{1 *}$, Masoud Hatefi ${ }^{2}$, Mina Roshani ${ }^{3}$, Reza Dadfar $^{4}$, Hematolah $^{6}$ Bastami $^{5}$, Marym Asdnahal ${ }^{6}$, Ali Sohrabnejad ${ }^{7}$

1. Department of Social Science, Faculty of Literature and Humanities, Ilam University, Ilam, Iran

2. Department of Neurology, Faculty of Medicine, Ilam University of Medical Science, Ilam, Iran

3. Department of General Psychology, Faculty of Literature and Humanities, Ilam University, Ilam, Iran

4. Shahid Beheshti University, Tehran, Iran

5. Department of Sport Management, Payame Noor University, Tehran, Iran

6. Imam Ali Hospital, Ilam University of Medical Science, Ilam, Iran

7. Department of Public Health, Faculty of Dentistry, Ilam University of Medical Sciences, Ilam, Iran

*Corresponding author:Tel: +98 9183430081 Fax: +98 8433300091

Address: Department of Social Science, Faculty of Literature and Humanities, Ilam University, Ilam, Iran

E-mail: Jahansham252@gmail.com

Received; 2017/06/16 revised; 2017/07/2 accepted; 2017/09/4

\section{Abstract}

Introduction: One of the common problems in contemporary world is addiction and its side effects. Dependency and addiction due to drug consumption is a chronic disorder which is followed by cultural, psychological, social, and spiritual effects. The aim of the present research was comparing behavioral-cerebral systems with alexithymia among addictive and normal people.

Materials and methods: The statistical population was all referred people to therapy centers of addiction in Ilam among which 40 cases were selected by accessible methods and also 40 cases of normal people without addiction background were selected based on their age, gender, education level, and married conditions by homogeneity procedure. Research method was comparative. Questionnaire of characterization by Wilson and questionnaire of Alexithymia by Toronto were used as research instrument to collect the data. Also, SPSS software and multi variable analysis were used to analysis the collected data.

Results: The findings showed that activated systems of behavior and fight-flight in people with addiction background was more than normal people, while behavioral deterrent system activities in normal people was more than people with addiction background $(\mathrm{P}<0.001)$. Also the mean scores of Alexithymia in people with addiction background was significantly more than that of normal people $(\mathrm{P}>0.001)$.

Conclusion: So, by identifying people that their behavioral activating system is more active than that of normal ones the risky group can be determined and then they can be benefited from behavioral and educational programs to be prevented from the likelihood of addiction in these groups. Also, cultivating capabilities of control and emotion regulation helps to prevent addiction and also helps people to adopt with changes and stress factors.

Keywords: Behavioral activation, Fight- flight, Alexithymia, Substance use

Copyright (C) 2018 Journal of Basic Research in Medical Science. This is an open access article distributed under the terms of the Creative Commons Attribution 4.0 International License (https://creativecommons.org/licenses/by/4.0/) which permits copy and redistribute the material, in any medium or format, provided the original work is properly cited. 


\section{Introduction}

Drug consumption and addiction is one of the main concerns and difficulties in contemporary world and since addiction have deterrent effects on society growth, so it is a serious problem. Wallis says: drug addiction is considered as chronic disorders with environmental, cultural, social, behavioral, and spiritual effects (1). The common procedure on addiction in the recent years in the world which is one of the most successful theoretical procedures is the procedure of addiction as a brain disease. With modifying literature on animal studies, Gray in the theory of reinforcement sensitivity introduces a biological paradigm from personality which is including three brain systems. Each system answers various subcategories of reinforcement events in a specific behavioral form. These systems also act by an inter-related separate collection of brain systems which process specific data (2).

The first system is behavioral activation system (BSA) that its structure includes several dopaminergic routes and circuits of cortical- striatum and Pulido Thalamic in the brain (CSPT). Neuro anatomy of the forehead cortex system is Amygdala and based basic knots (2) which are activated by pleasant stimulus related to rewards or removing punishment. Two behavioral components of this system are including: active search for reward and active avoidance (punishment avoidance). Sensitivity of this system shows individual early arousal (3). The second system is behavioral inhibition system (BIS) which is the byproduct of activities afferent neuro adrenergic and Serta neuralgic.

Neuroanatomy of behavioral punishment system is in hippocampus system, brain stem, and Popes circuit and forehead cortex. These structures lead to arousal increasing and negative affection (3) and have commonalities with anxiety systems. So, BIS system has concordance with anxiety sense, concern, and thought rumination (4). Fight - flight system is the third behavioral- cerebral system that is related to amygdale and hypothalamus (5) which elicits avoidance, Flight, and fear behavior for conditioned and non conditioned stimulus (6). About addiction, most attention is on behavior activated system. Many studies indicated that behavioral hyperactivity play an important role in alcohol consumption among girls (7), alcohol consumption among men and women (8), cigarette smoking (9) and addiction (10).

Although various studies investigated the importance of behavioral activated system in drug abuse, but the role of behavioral inhibition and fight-flight-freeze system (FFFS) is not clear and the findings are contradicted. While some studies indicated that there is a negative relationship between BIS system and drug abuse (11) some others have found no relationship between BIS system and drug abuse (7).

Besides cerebral- behavioral activity, among various factors related to drug abuse the outstanding role of emotional problems and disability in the control and regulation of emotions generally and Alexithymia specifically can be indicated. Alexithymia means have problems in emotion and self-regulating; in other words, it means disability in cognitive process of emotion data (12). Alexithymia is a multi-dimension structure including difficulty in identifying the sensations, difficulty in describing the sensations for others and external thought tendency (13), main features of alexithymia are including: disability in retrieving and verbal description of individual emotion, poverty of symbolic think which limited feedback drive, sensations and tendencies, disability in using sensation as sign of emotional problems, abstract thinking about negligible realities, decreasing the remembrance of dreams, difficulty in the distinction between exciting modes and 
physical senses, formal appearance, lacking emotional modes of face, limited capacity for self - awareness and empathy (14).

Alexithymia is lacking in process understanding and emotion description which leads to preparedness of some people to drug addiction (15), also the (15) emotions of addictive people is similar to that of children and is in preverbal level and their injured cognitive capacity leads to lacking in process understanding, depression, and anxiety (15). In this condition, capacity of delaying reaction to skills is low and so a type of contradiction between the individual and environment is increased and the individual frequently experience stress while facing emotion (15). The finding of keen (14), Lindsay and Siaroochi (16), Hamidi, Rostami, Farhoodi and Abdolmanafi (15) Delvar showed that there is a significant difference between the three subcategories of mode alexithymia in addictive and normal people. Also, Thorbrg, Yong, Silvan and Lyvers (16) in their study indicate that there is a direct relationship between alcohol consumption and alexithymia. Regarding these factors, disorders of behavioral- cerebral systems and disability in the controlling and regulation of emotions play an important role in tendency toward drug consumption, so the present research was done aiming at comparing behavioral- cerebral systems with alexithymia among addictive and normal people in Ilam.

\section{Materials and methods}

The present research was a post event research and its procedure was causativecomparative in which two groups, addictive people and normal ones, were compared in view of behavioral-cerebral systems and alexithymia. In causativecomparative researches, the main aim is investigating the probability of relationship between variables by observing results and exact investigating of the data to find accurate causative variables (17). Research population is including all affected people referred to therapy centers of addiction in the city of Ilam.

Research sample and sampling method: Research sample was including 40 addictive people that their background were recorded in addiction centers and 40 normal people without addiction background which were selected by accessible method and they were homogenized based on their age, gender, education level, and married conditions. In comparative- causative method each subcategory must include at least 15 cases.

Research instrument: The questionnaire of characterization by Gray-Nelson was used which includes 120 cases among which 40 items were considered for each variable of inhibition system, behavioral activation, and fight avoidance. Each of these categories has two factors, 20 items were considered for each factor. Behavioral activate system is including two factors of turned and active avoidance, inhibition system is including two factors of passive avoidance and silence and the system of challenges has two factors of fight and flight. (18). In the study of GrayWilson, Cronbach's alpha for coping, active avoidance, passive avoidance, fight, and flight was $0.71,0.61,0.58,0.61,0.65$, 0.65 , for males and $0.68,0.53,0.63,0.71$, 0.71 , for females, respectively (19). For evaluating psychological characteristics in this questionnaire, Cronbach's alpha for coping, active avoidance, passive avoidance, silence, fight, was $0.60,0.54$, $0.61,0.66,0.65$ and 0.69 for males and $0.53,0.57,0.52,0.64$, and 0.64 for females respectively. Cronbach's alpha for this scale was $0.65(21)$.

Questionnaire of TAS-20: It is a questionnaire with 20 items which was developed by Bagby, Taylor (11) and it measures alexithymia in three sub-scales; the scales of identifying senses (7 items), difficulty in describing sensations (5 items) and think about aim ( 8 items) by 5 scales of Likert from 1 (strongly disagree) 
to 5 (strongly agree) (12). In the Persian version, Cronbach's alpha was 0.85 for alexithymia and for three subs-scales of identifying senses, difficulties in describing sensations, and think about out was $0.82,0.75$, and 0.72 , respectively, that was confirmed. As it was indicated by Hamidi and et al (15), Cronbach's alpha of Persian version for identifying sensations is 74, for difficulty in describing sensations it is 0.61 , and for external think is 0.50. Also he indicated that total reliability of Persian scale is 0.74 and for difficulty in describing sensation is 0.70 , difficulty in identifying sensations is 0.64 , and external think is 0.52 . In the present research, Cronbach's coefficient was 0.65 .

\section{Results}

In table 1 , descriptive data of the variables is presented. In the table, the means of behavioral activation, behavioral inhibition, fight-flight and mode alexithymia have been shown. In normal people, the values are ranged from 29.50 to 46.65 . In addicted group, the values are ranged from 32.32 to 64.63 .

Regarding the rates of $\mathrm{F}$ depicted in table 2, scores are as followed: behavioral activation (68.33), behavioral inhibition (41.31), fight-flight (18.73) and alexithymia (110.16) and sig of all of them are smaller than 0.001 . So hypothesis of equality in means of behavioral activation, fight-flight, and alexithymia in behavioral inhibition addictive and normal people is rejected with high reliability.

Regarding the obtained results of multivariate analysis of variance of difficulty in identifying sensation, difficulty in describing sensations and focus on external experiences scores, the hypothesis of equality of means of these three variables are rejected $(\mathrm{P}<0.001$, $\mathrm{F}=35.03, \quad \mathrm{~F}=157.25$ and $\mathrm{F}=11.19$, respectively). The rate of these three variables scores in addictive people is more than, that of normal people.

Table 1. Mean \pm standard deviation of scores of variables behavioral activation, behavioral inhibition, fightflight, and alexithymia in two groups of addicted and normal people.

\begin{tabular}{lcc}
\hline Variable & Normal group & Drug abused group \\
\hline Behavioral activation & $34.87 \pm 50.6$ & $45.32 \pm 6.09$ \\
Behavioral inhibition & $43.75 \pm 7.56$ & $32.32 \pm 8.31$ \\
Fight-flight & $29.50 \pm 9.41$ & $38.97 \pm 10.15$ \\
Mode alexithymia & $46.65 \pm 8.47$ & $64.63 \pm 6.72$ \\
\hline
\end{tabular}

Table 2. Results of multi-variance analysis of behavioral activation, fight-flight, and alexithymia for comparing mean score of addictive and normal people.

\begin{tabular}{lccccc}
\hline Variable & Sum of squares & df & Mean of squares & F & P value \\
\hline Behavioral activation & 2184.05 & 1 & 2184.05 & 33.68 & 0.000 \\
Behavioral inhibition & 2610.61 & 1 & 2610.61 & 41.31 & 0.000 \\
Fight-flight & 1795.51 & 1 & 1795.51 & 18.73 & 0.000 \\
Mode alexithymia & 6444.05 & 1 & 6444.05 & 110.16 & 0.000 \\
\hline
\end{tabular}

\section{Discussion}

The findings of the present research indicated that addictive people in comparison with normal ones have higher activity and sensitivity in behavioral activation system. This finding is in agreement with $(7-10,18)$. To describe the difference, it can be said that based on the theory of sensitivity to reinforcement, normal and abnormal personality are in the same continuum. So those people who are in the extreme dimensions of behavioral activation system and behavioral inhibition system are confronting with extending pathology symptoms more than others (21). In the framework of psychopathology, by developing the theory of behavioral-cerebral systems theory, Gray believed that disordering is the 
reflection of reaction in one of the systems, dysfunction in a system, reaction or dysfunction in more than one system or dysfunction in a system, combining more or less reaction on addiction, and majority of findings about performance of this system are derived from human investigation related to dopamine. Dopamine routes about stimulus and emotion are important in a way that their main task is providing positive sensation such as experience, enjoyment, and reward (22). In other words, people with high sensitivity in BAS are more vulnerable for positive experience about stimulus and reward (7), so overcome to BAS and high sensitivity on reward signs show biological factors in people with tendency toward addiction.

Although high sensitivity of BAS is considered as a personality factor but this assumption cannot be ignored that high levels of BIS is because of drug abuse Some studies indicated that personality dimensions of addictive people are changing during time (11, indicated by Potenza (1) By considering this point, we would have no certain conclusion about the relationship between BAS and addiction and it needs more investigations. Also other findings of the study are indicating that activity and sensitivity of normal people in inhibition system is higher than that of addictive people.

About differences of addictive and normal groups on inhibition system it can be said that based on Gray motivational theory (23), this system is a neurological system in which enjoyment signs are activated by its weakness which leads to releasing sensation in individual. Low sensitivity of this system can provide enjoyment and the possibility of altitude toward experience drugs is increased. (18) Some researchers believe that weakness of the system in addictive people is indicating their less sensitivity toward punishment and their problem in adopting with social punishment. But those people who have more active system have high anxiety and stress in confronting with cigarettes or drug which leads to flight from dangerous position which in turn brings them sensation of relaxation (24). Knyazey (25) is indicating the role of this system as a supportive factor in fact this system prevents individual from dangerous positions. Because of lack of emotional awareness and disability in cognitive process of their sensations these people cannot identify and describe their emotion and have a limited capability in adopting with challenged conditions. One of the methods for controlling of challenges especially about negative emotion is discharging and indicating to the emotion. If these emotions are not discharged and if they cannot indicate their negative emotions verbally depression and anxiety would increase (26), finally it may lead to drug consumption for decreasing these symptoms and reducing the rate of stress and anxiety.

\section{Conclusion}

About differences between groups we concluded that the rate activity of fight flight system in addictive people in comparison with normal people is higher, so it can be said that regarding the revised theory of Gray, fight-flight system is responsible for answering to conditional and none conditional stimulus such as punishment (5). It is indicated that fear is a defensive reaction which is appeared by fight-flight system in a special position and is realized as a behavioral display. Drug abuse also is a kind of people's confrontation with stress which is appeared as negative emotions or avoidance (27). Also other findings of this study showed that addictive people are weaker than normal people in identifying, describing, and externally-oriented thinking of their emotions it can be said that Alexithymia is an emotional personality in which individual is unable in understanding and describing his/ her emotion. When exciting data cannot be measured in cognitive process, the 
individual is cognitively and emotionally depressed and unable and this disability in adopting with their problem would disturb his/ her organization of emotions.

\section{References}

1. Potenza MN. Non substance and substance addictions. Addiction. 2009;104(6):1016-7.

2. Hewig J, Hagemann D, Seifert J, Naumann E, Bartussek D. The relation of cortical activity and BIS/BAS on the trait level. Biol Psychol. 2006;71(1):42-53.

3. Markarian SA, Pickett SM, Deveson DF, Kanona BB. A model of BIS/BAS sensitivity, emotion regulation difficulties and depression anxiety and stress symptoms in relation with sleep quality.J Psychiatry Res. 2013;210(1):281-6.

4. Ilsec IVB, kranenburg Tw, Schaufeli WB. BIS - and BAS - activation and study outcomes: AMedication study. J Psychiatry Res. 2007; 55(2013): 474-9.

5. Mc-Naughton N, Corr PJ. A twodimensional neuropsychology of defense: Fear/anxiety and defensive distance. Neurosci Biobehav Rev. 2004;28(3):285-305.

6. Bijttebier P Beck, I ClaesLVandereycken W. Gray's reinforcement sensitivity theory as a framework for research on personalitypsychopathology associations. Clin Psychol Rev. 2009;29(5):421-30.

7. Loxton NJ, Dawed. Reward and punishment sensivity in functional eating and hazardous drinking women: association with family Risk. Appetite. 2006; 47(3): 361-71.

8. PardoY, Aguilar R, Molinuevo B, Torrubia R. Alcohol use as a behavioral sign of disinhibit ion: Evidence from J.A. Gray's model of personality. J Addictive Behave. 2007; 32 (10): 2398-403.

\section{Acknowledgment}

The authors acknowledge the Ilam University for financial supporting of this research study.

9. O'Connor R M, Stewart SH, Watt M. Distinguishing BAS risk for university student's drinking, smoking, and gambling behaviors. Pers Individ Dif. 2009;46 (4): 514-9.

10. Franken IHA, Muris P, Georgieva I. Gray's model of personality and addiction. Addict Behav. 2006;31(3):399-403.

11. JTaylor GJ, Bagby M, Parker JD. An overview of the alexithymia construct. In: Bar-On R, Parker JD. (Editors). The handbook of emotional intelligence. $1 \mathrm{st}$ ed. San Francisco: Jossey-Bass; 2000: 200-206.

12. Lindsay J, Ciarrochi J. Substance abusers report being more alexithymia than other but do not show emotional processing deficits on a performance measure of alexithymia. Addict Res Theor. 2009; 16(3): 315-21.

13. Bagby RM, Taylor GJ, Parker JD. The twenty -item Toronto Alexithymia scale - II convergent an discriminant, and concurrent validity. J Psychosom Res. 1994;38(1):33-40.

14. Sussman S, Lisha N, Griffiths $M$. Prevalence of the addictions: a problem of the majority or the minority? Eval Health Prof. 2011;34(1):3-56.

15. de Haan HA, van der Palen J, Wijdeveld TG, Buitelaar JK, De Jong CA. Alexithymia in patients with substance use disorders: state or trait? Psychiatry Res. 2014;216(1):137-45.

16. Thorbrg FA, Young RM, Sullivan KA, Lyvers M. Alexithymia and alcohol use disorders: A critical review. Addict Behav. 2009;34(3):237-45.

17. Grant TE, Potenza MN, Weinstein A. Introduction to behavioral addictions. 
Am J Drug Alcohol Abuse. 2010; 36(5): 233-41.

18. Sharifi M, Javanmard GH. A comparative study of problem solving styles and mental health in male substance abusers and normal men. Psychol Behav Sci. 2017; 6 (3): 36-42.

19. Shekhar S, Fahmy H. Dignity- a fundamental principle of mental health care. J Med Res. 2015; 142 (4): 35558.

20. Gray JA. Framework for taxonomy of psychiatric disorder. In S. H. M. van Goozen, N. E. Van de poll - J. A. sergeant (Eds.), Emotions: Essay on emotion therapy, Lawrence Erlbaum Associations. 1994: 29-59.

21. Hoyle RH. The neuroscience of personality. Handbook of personality and self-regulation. Sons, Ltd. BlackWell Publication. 2010:20-30.

22. Ashby FG, Isen AM, Turken AU. A neuropsychological theory of positive affect and its influence on cognition. Psychol Rev. 1999;106(3):529-50.
23. Babapor G, Dadashzadeh R, Tosi F. A social neuroscience perspective on adolescent risk taking. Dev Rev. 2008;28(1):78-106.

24. Shahgholian M, Moradi A, Kafi SM. [Relation of alexithymia with emotional expression styles and general health in students]. Iran $\mathbf{J}$ Psychiatr Clin Psychol. 2007;13(3):238-48. (Persian)

25. Knyazev GG. Behavioural activation as predictor of substance use: mediating and moderating role of attitudes and social relationships. Drug Alcohol Depend. 2004;75(3):309-21.

26. Nolen-Hoeksema S. Gender differences in risk factors and consequences for alcohol use and problems. J Clin Psy Rev. 2004; 24(8): 981-1010.

27. Besharat MA, Shahidi S. What is the relationship between alexithymia and ego defense styles? A correlational study with Iranian students. Asian J Psychiatr. 2011;4(2):145-9. 